\title{
Avaliação da sustentabilidade do Plano das Bacias dos rios Piracicaba, Capivari e Jundiaí 2020-2035: análise dos indicadores de disponibilidade e demandas hídricas
}

\section{Sustainability assessment of the Piracicaba Capivari and Jundiai 2020-2035 River Basin Management Plan: analysis of water availability and demand indicators}

\author{
Cibele Roberta Sugahara ${ }^{i}$ \\ Orcid: https://orcid.org/0000-0002-3481-8914 \\ Lorena Braga Quintella Jucáiii \\ Orcid: https://orcid.org/0000-0001-9313-9375
}

\author{
Audrey Moretti Martins ${ }^{\text {ii }}$ \\ Orcid: : https://orcid.org/0000-0003-1883-1622 \\ Duarcides Ferreira Mariosa ${ }^{\text {iv }}$ \\ Orcid: https://orcid.org/0000-0001-6552-9288
}

\begin{abstract}
Resumo
A água, recurso natural fundamental para a vida humana, está heterogeneamente distribuída no planeta. No âmbito das bacias hidrográficas dos rios Piracicaba, Capivari e Jundiaí, a preocupação com o atendimento das necessidades da população, de forma perene e sustentável, e melhorias das condições do balanço hídrico têm suscitado ações por parte das Agências reguladoras. O objetivo do trabalho é analisar os Programas de Gerenciamento de Recursos Hídricos do Plano de Bacias PCJ, visando apontar como o modelo de avaliação dos princípios de Gibson pode ser adotado a fim de garantir a sustentabilidade das bacias. A metodologia adotada é de natureza qualitativa, descritiva e exploratória com procedimento técnico documental. Dentre os resultados observa-se a presença de ações que colaboram para a identificação de demandas por sub-bacia e auxiliam no controle de perdas em sistemas de abastecimento de água. Conclui-se que o modelo de avaliação da sustentabilidade de Gibson pode contribuir para acompanhar a evolução das metas e indicadores quanto à espacialização das demandas e do saldo hídrico.

Palavras-chave: avaliação de sustentabilidade; bacias pcj; indicadores de sustentabilidade; disponibilidade hídrica; demandas hídricas.
\end{abstract}

\begin{abstract}
Water, a central natural resource for human life, is heterogeneously distributed on the planet. Regarding the river basins of the Piracicaba, Capivari and Jundiaí rivers, the concern with meeting the needs of the population in a permanent and sustainable way and improvements in the conditions of the water balance has given rise to actions by the regulatory Agencies. The objective of the work is to analyze the Water Resources Management Programs of the PCJ Basin Plan, specifically how the Gibson principles assessment model can be adopted in order to guarantee the sustainability of the basins. The adopted methodology is of qualitative, descriptive, and exploratory nature with documentary technical procedure. Among the results, there is the presence of actions that collaborate to identify demands by sub-basin and assist in the control of losses in water supply systems. It is concluded that Gibson's sustainability assessment model can contribute to monitor the evolution of goals and indicators regarding the spatialization of demands and the water balance.
\end{abstract}

Keywords: sustainability assessment; pcj basins; sustainability indicators; water availability; water demands.

\footnotetext{
${ }^{\text {i }}$ Pontifícia Universidade Católica de Campinas - PUC Campinas, Brasil. E-mail: cibelesu@puc-campinas.edu.br

ii Universidade de Araraquara - UNIARA, Brasil. E-mail: audreymartins@usp.br

iii Universidade de São Paulo, Brasil. E-mail: lorenabraga@usp.br

iv Pontifícia Universidade Católica de Campinas - PUC Campinas, Brasil. E-mail: duarcides@gmail.com
} 


\section{INTRODUÇÃO}

Numa teia de relações cada vez mais complexas, em que os desafios postos pela modernidade são de difícil solução, a administração sustentável de recursos essenciais à vida humana exige muito mais do capital humano, "construto composto pelos saberes, talentos e competências das pessoas", do que outrora nos era oferecido somente pelo acúmulo de máquinas, equipamentos, construções e mão de obra (AMORIM et al., 2015, p. 151).

Nesse aspecto, ainda que em diversos momentos históricos desequilíbrios entre o meio ambiente, a sociedade e as atividades econômicas tenham se tornado realidade, o conceito de desenvolvimento sustentável mais reconhecido foi apresentado anos antes, no relatório Nosso Futuro Comum, denominado Relatório da Comissão de Brundtland. Esse documento divulgado pela Comissão Mundial sobre Meio Ambiente e Desenvolvimento - CMMAD (1988, p. 46) define o desenvolvimento sustentável como aquele "que atende às necessidades do presente sem comprometer a capacidade das gerações futuras de atenderem às suas necessidades". Não obstante, as noções de sustentabilidade e de desenvolvimento sustentável adquirem força e solidez somente a partir de 1992, marcando a entrada oficial da pauta meio ambiente nas agendas políticas dos países. Isso denota que tais conceitos são relativamente novos e que se consolidam como uma preocupação política, social, econômica, institucional e cultural somente após a percepção dos sinais de esgotamento dos recursos naturais, dos efeitos da mudança climática e da alteração dos ritmos bióticos que poderiam levar a um colapso das civilizações (DIAMOND, 2005).

Entretanto, a despeito da crescente preocupação com $\mathrm{o}$ equilíbrio entre $\mathrm{o}$ capital natural e o progresso econômico observa-se, como defende Menezes, Dias e Gomes (2010), a existência de um distanciamento quanto às práticas de gestão sustentáveis amparadas por uma prática social e cultura de gestão responsável.

$\mathrm{O}$ enfoque da gestão de recursos ou ativos ambientais escassos, fundamentais e insubstituíveis para o provimento de serviços de suporte à vida, é adotado nos trabalhos de Kates; Parris e Leiserowitz (2005), e Ayres, Van Den Bergh e Gowdy (1998) alinhados ao conceito de desenvolvimento sustentável empregado pelo Relatório da Comissão de Brundtland. A noção de desenvolvimento sustentável abrange aspectos relacionados aos desafios ambientais globais, à capacidade de resposta da extensão de danos ambientais, questões de ordem política, entre outros. Esse conceito tal qual foi designado pela CMMAD representa, segundo Mebratu (1998), um marco político conceitual. E mais, pensar a sustentabilidade nos diferentes contextos histórico e geográfico envolve a elaboração de estudos de caráter multi, inter e transdisciplinares. $\mathrm{O}$ alcance da sustentabilidade apresenta desafios, tais como: integrar o tripé "economia, ambiente e sociedade", além de questões institucionais; dimensionar os impactos das ações presentes no futuro; e conscientização, educação ambiental e participação social (SARAIVA et al., 2019; SARTORI; LATRÔNICO; CAMPOS, 2014).

$\mathrm{Na}$ pesquisa da qual originou $\mathrm{o}$ presente texto, aborda-se, portanto, o conceito de desenvolvimento sustentável a partir da orientação para o progresso econômico e social, no que se refere à dimensão do capital natural e de políticas transversais para a gestão da água em bacias hidrográficas.

A bacia hidrográfica é o elemento fundamental de análise do ciclo hidrológico, sendo descrita por Collischonn e Dornelles (2015) como a área de captação natural dos fluxos de água originados da precipitação, onde os escoamentos convergem para um único ponto de saída, denominado exutório. De acordo com 
Slimane (2012) e Sartori, Latrônico e Campos (2014), as condições de sustentabilidade em escala regional e nacional não são necessariamente as mesmas, tendo em vista os mecanismos de transferência geográfica. Por isso, é importante considerar a conformação territorial para a aplicação do conceito de desenvolvimento sustentável no contexto da sustentabilidade e segurança hídrica das bacias hidrográficas.

Complementarmente, os indicadores e índices correspondentes são ferramentas de suma importância para a gestão dos recursos hídricos. Indicadores simplificam e quantificam dados com o intuito de avaliar e mensurar a sustentabilidade hídrica na região, compondo um diagnóstico com a finalidade de, posteriormente, servir de base para a montagem de um plano de ação que irá atacar as fragilidades detectadas, propor melhorias e elaborar soluções (HUESEMANN, 2004; SARTORI; LATRÔNICO; CAMPOS, 2014; SICHE et al., 2008). Logo, ao desenvolver e aplicar indicadores de sustentabilidade, esses devem considerar as particularidades de uma região, do contrário, eles estarão sujeitos à ineficácia ou comprometimento do processo de tomada de decisão (SARTORI; LATRÔNICO; CAMPOS, 2014)

Por sua vez, a avaliação da sustentabilidade é um processo dinâmico, integrado e abrange aspectos sistêmicos, além das dimensões social, ambiental e econômica. Entre as diversas opções de modelos de avaliação, o modelo de Gibson contempla um conjunto de elementos centrados no ecossistema que remete a questões sociais, como justiça e equidade. A proposta baseada no modelo de Gibson permite uma avaliação da sustentabilidade que considera, sobretudo, as interconexões entre as questões, objetivos, ações, efeitos e resultados (GIBSON, 2006, p. 268).

No caso das Bacias dos rios Piracicaba, Capivari e Jundiaí (PCJ), o
Plano das Bacias PCJ 2020-2035, fruto de um amplo estudo realizado por profissionais contratados para esse fim, sob orientação das Câmaras Técnicas e acompanhamento público, desenhou diversos cenários para implementação de projetos com ações e metas até o ano de 2035. Em que pese que, em muitos casos, se estendam até 2050, já que o estudo demonstrou que alguns projetos precisarão ser implementados no mais longo prazo. Entre as tarefas mais imediatas para os gestores está a criação de uma plataforma de indicadores para acompanhar a efetividade das ações previstas e em curso e as discussões que integram a elaboração e aprovação de um modelo de gestão apropriado ao planejamento previsto (AGÊNCIA DAS BACIAS PCJ, 2020; CONSÓRCIO PROFILL-RHAMA PCJ, 2020b).

A abordagem de sustentabilidade adotada pelo Comitê de Bacias Hidrográficas dos rios Piracicaba, Capivari e Jundiaí (CBH-PCJ) contempla uma visão integrada de gerenciamento de recursos hídricos, como evidenciado no Relatório Síntese 2020-2035 (CONSÓRCIO PROFILL-RHAMA PCJ, 2020b).

Os apontamentos sobre a sustentabilidade das Bacias PCJ são realizados a partir de informações a respeito do balanço hídrico. Posto isso, julga-se necessário elucidar alguns conceitos hidrológicos. Conforme consta no Relatório Síntese, o balanço hídrico é tido como "o balanço entre as demandas consuntivas e as vazões de retorno. Também são consideradas as transposições e as reversões nas Bacias e a vazão regularizada por reservatórios" (CONSÓRCIO PROFILLRHAMA PCJ, 2020b, p. 64). Collischonn e Dornelles (2015) definem uso consuntivo da água como aquele que altera consideravelmente a quantidade de água disponível para outros usuários - como o uso para irrigação, por exemplo enquanto o uso não-consuntivo pouco modifica a quantidade de água disponível, 
mas que, porém, pode alterar sua qualidade, como o uso para geração de energia hidrelétrica. Já as vazões de retorno correspondem à parcela de vazão retirada para um determinado uso - como o uso doméstico - que retorna ao manancial (por exemplo, esgotos decorrentes do uso da água para abastecimento humano).

Também é relevante destacar a disponibilidade hídrica em relação às demandas que contemplam o setor de abastecimento urbano, setor industrial, setor irrigante e demanda para dessedentação animal. A disponibilidade hídrica é adotada na gestão dos recursos hídricos como uma estimativa da quantidade de água que está disponível para uma variedade de usos, a citar, a irrigação, abastecimento e lançamento de efluentes, baseada em vazões mínimas ou vazões de estiagem (ANA, 2020). Desse modo, a "capacidade do meio ambiente de atender às necessidades presente e futuras" (MEBRATU, 1998 p. 501), quanto ao provimento da água em quantidade e qualidade, deve ser abordada a partir da capacidade de suporte das bacias hidrográficas. O que de certa forma é amparado pelos Planos de Bacias, desenvolvidos nas diversas agências encarregadas da gestão dos recursos hídricos no país (ANA, 2019), mas que deixa um certo ceticismo quanto à capacidade ambiental de suporte às necessidades de consumo sempre crescentes da população.

Diante do exposto, a temática tratada neste texto diz respeito à possibilidade de avaliação da sustentabilidade do balanço hídrico nas Bacias PCJ, com o intuito de propor reflexões que contribuam para o atendimento da demanda de água em diferentes contextos, propondo-se responder a seguinte indagação: afinal, em que medida o modelo de avaliação da sustentabilidade para o contexto das Bacias PCJ, pautado nos critérios e processos para avaliação de sustentabilidade propostos por Robert Gibson e Selma Hassan (GIBSON;
HASSAN, 2005), poderia ser utilizado para essa finalidade?

Metodologicamente amparados em pesquisa de base documental, de natureza qualitativa, descritiva e exploratória, o objetivo do trabalho é analisar os Programas de Gerenciamento de Recursos Hídricos do Plano de Bacias PCJ, visando apontar como o modelo de avaliação dos princípios de Gibson pode ser adotado a fim de garantir a sustentabilidade das bacias.

\section{FUNDAMENTAÇÃO TEÓRICA}

\subsection{Avaliação de sustentabilidade}

Diante das mudanças, riscos e incertezas que pairam sobre os âmbitos político, econômico, ambiental, social, cultural e tecnológico do cenário global, sistemas de medição e avaliação de sustentabilidade foram pensados para dar suporte ao desenvolvimento de políticas públicas, programas, ações e no processo de tomada de decisão. A avaliação de sustentabilidade emerge como um processo que utiliza integração, síntese, abordagens sistêmicas, gestão de compensações (também designados trade-off), pluralismo de ferramentas e abordagens colaborativas para solucionar problemas, a partir de novos modelos ou da otimização de modelos já existentes, tendo em vista o desenvolvimento sustentável (HODGE; HARDI; BELL, 1999; NESS et al., 2007).

Partindo-se do pressuposto de que o desenvolvimento é uma construção social e depende da evolução de longo prazo de sistemas extremamente complexos - a população humana e a economia incorporadas aos fluxos biogeoquímicos dos ecossistemas do planeta - os indicadores são imperfeitos, por isso tem-se como desafio reduzir a incerteza desse ambiente (MEADOWS, 1998, p. 7).

Conceitualmente, a sustentabilidade precisa ser pensada a partir de modelos e processos. São os modelos que podem mais facilmente orientar as decisões rumo ao desenvolvimento sustentável. Cada modelo 
de avaliação de sustentabilidade possui atributos que permitem avaliar o processo da sustentabilidade em si. A avaliação da sustentabilidade fornece um panorama com dados comparáveis do cenário que se quer examinar, para que, através das lentes da sustentabilidade, tal cenário possa ser alinhado ao conceito de desenvolvimento sustentável, a partir da gestão de indicadores e da proposição de ações e metas.

Uma avaliação de sustentabilidade pode ser realizada para avaliar uma situação já existente (ex-post) ou antes de sua concretização (ex-ante). Em consequência, ela fornece sinais de alerta para elaboração de políticas, planos, programas e projetos; mudanças comportamentais; assumir responsabilidade; reconhecer boas práticas; facilitar o processo de aprendizagem contínuo; identificar lacunas de conhecimento e atuar no seu preenchimento (HODGE; HARDI; BELL, 1999).

Hodge, Hardi e Bell (1999) destacam quatro problemas ou vícios que são comuns às metodologias de medição: agregação, ponderação, unidades e escala. Para a análise da sustentabilidade do balanço hídrico nas Bacias do PCJ, agregação diz respeito a quais variáveis ou conjunto de indicadores serão considerados; como serão ponderados, isso é, qual o peso que será dado a cada fator, variável ou indicador; quais unidades serão consideradas na análise; e, por fim, a escala, relacionada ao nível de decisão. Conforme a escala aumenta, também aumenta a amplitude (em termos espaciais, de território e de pessoas, por exemplo).

Posto dessa forma, e considerando os limites e possibilidades de cada caso, as ferramentas empregadas na avaliação de sustentabilidade oferecem abordagens para medir e avaliar mudanças e progressos, tendo como foco a integração, isso é, a união de aspectos ambientais, sociais e/ou econômicos, a nível estratégico ou de projeto (NESS et al., 2007). Dentro do contexto de uma sub-bacia hidrográfica, cita-se como referência o trabalho de Carvalho, Carvalho e Curi (2011) que exploram essa integração na avaliação de sustentabilidade de municípios pertencentes a uma sub-bacia, utilizando um modelo de avaliação multicritério com indicadores que envolvem as dimensões social, demográfica, econômica e ambiental. Tal feito viabilizou a criação de um índice de sustentabilidade para auxiliar na tomada de decisão. Visto isso, considera-se relevante escolher modelos de avaliação que sejam transversais e tenham uma abordagem sistêmica, como é o caso do modelo de Gibson.

\subsection{Modelo de Gibson}

Uma das ferramentas para a avaliação da sustentabilidade é o modelo de Gibson, composto por um conjunto de critérios que rompe com as falhas das avaliações convencionais. Isso porque esse modelo considera as dimensões ambiental, social e econômica do tripé da sustentabilidade, de forma integrativa e sem ocasionar sobreposições entre elas, o que possibilita maior integração dos sistemas social e ecológico, sem necessariamente privilegiar trade-offs, ou seja, sem mitigar seus efeitos utilizando-se qualquer forma de compensação.

Para tanto, o autor propõe os seguintes critérios ou princípios para avaliar a sustentabilidade (GIBSON, 2006):

I) Integridade do sistema socioecológico;

II) Recursos suficientes para subsistência e acesso a oportunidades;

III) Equidade intrageracional;

IV) Equidade intergeracional;

V) Manutenção de recursos naturais e eficiência;

VI) Civilidade socioambiental e governança democrática;

VII) Precaução e adaptação; e

VIII) Integração entre situação atual e de longo prazo. 
A abordagem dos princípios de Gibson (2006) está amparada no interrelacionamento entre os seus elementos, além de privilegiar um processo participativo e dialogado para a sua aplicação, o qual considera, sobretudo, as particularidades do contexto na avaliação da sustentabilidade. A descrição dos atributos de cada princípio com base no trabalho de Gibson (2006) é relatada a seguir.

O primeiro princípio Integridade do sistema socioecológico refere-se à construção de relações humanoecológicas que primam pelo estabelecimento e preservação da integridade de longo prazo de sistemas sócio e biofísicos (capacidade de suporte), além de zelar pelas funções de suporte à vida, insubstituíveis para o bem-estar humano e do plano ecológico. Capacidade suporte ou capacidade de carga implica que o recurso de uma determinada região pode ser utilizado por um número limitado de pessoas, sem que a qualidade ambiental seja prejudicada (SILVA, 2009).

Quanto ao princípio dois Suficiência de meios de subsistência e oportunidade - a ênfase está em garantir aos indivíduos $\mathrm{e}$ às comunidades $\mathrm{o}$ suficiente para uma vida decente, além da oportunidade de melhorias que não comprometam o futuro destas e de novas gerações.

No que tange ao princípio três Equidade intrageracional - Gibson refere-se à suficiência de escolhas eficazes para suprir as necessidades essenciais de todos os indivíduos (saúde, educação, reconhecimento social, estima) e diminuir as desigualdades sociais.

Já o princípio quatro - Equidade intergeracional - diz respeito às escolhas que permitam preservar ou gerar oportunidades às novas gerações para uma vida digna, includente e sustentável.

O quinto princípio - Manutenção de recursos naturais e eficiência consiste em fornecer uma ampla base para a garantia de meios de subsistência mais sustentáveis para todos, ao passo em que se reduz as ameaças à integridade de sistemas socioecológicos no longo prazo, evitando a geração de resíduos e reduzindo o consumo de matéria e energia.

O sexto critério - Civilidade socioecológica e governança democrática - diz respeito a gerar capacidade, motivação e propensão em indivíduos, comunidades e demais órgãos tomadores de decisões coletivas para pensar e promover requisitos de sustentabilidade, através de um processo decisório aberto e bem informado, mais atento à promoção de uma consciência recíproca e senso de responsabilidade coletiva, além de práticas mais integradas em decisões administrativas, de mercado, habituais e pessoais.

Já o sétimo princípio - Precaução e adaptação - contempla incertezas e evita ações com potenciais riscos que comprometam a sustentabilidade do ecossistema. Esse critério busca mitigar danos graves ou irreversíveis aos recursos naturais. Por isso, é importante contar com uma gestão adaptativa e preventiva, fomentando o aprendizado contínuo.

Por fim, o oitavo princípio Integração entre situação atual e de longo prazo - visa à aplicação de todos os princípios de sustentabilidade, concomitantemente, em busca de benefícios mútuos e ganhos múltiplos. Inicia-se a partir da premissa de integrar, em que a questão ambiental, segundo Hacking e Guthrie (2007), assume outra abordagem, ou seja, vai além dos aspectos biofísicos, levando em consideração também aqueles relacionados à qualidade de vida e crescimento. De acordo com MorrisonSaunders e Pope (2013), a integração de curto e longo prazos pode trazer ganhos como a diminuição da guerra entre os pilares da sustentabilidade, melhoria e coerência nas ações adotadas, além de proporcionar ajuda para identificar soluções "ganha-ganha-ganha" entre os pilares.

A avaliação da sustentabilidade com a abordagem de Gibson busca mais do que 
o equilíbrio entre os critérios econômicos, sociais e ambientais, ao reforçar a construção coletiva, com participação social, e atribuir igual importância aos oito princípios no processo de avaliação (MORRISON-SAUNDERS; POPE, 2013; GIBSON, 2006). O primeiro aspecto a ser atendido ao aplicar a avaliação de sustentabilidade em questão refere-se à elaboração de perguntas norteadoras, construídas a partir de um processo de participação e diálogo entre os envolvidos, direta ou indiretamente, na avaliação. Busca-se decifrar as questões e, em seguida, são identificados os pontos fracos $\mathrm{e}$ oportunidades de melhoria, com base na análise das respostas. Posteriormente, é possível propor estratégias e indicadores que guiarão a tomada de decisão dos gestores e outros atores envolvidos no processo (GIBSON, 2006).

\section{METODOLOGIA}

\subsection{Caracterização da pesquisa}

O método de trabalho deste estudo caracteriza-se como qualitativo descritivo e de caráter exploratório. Richardson (2017) destaca que os estudos de natureza descritiva têm por objetivo investigar as características e aspectos de um fenômeno. Esse tipo de trabalho considera como objeto de estudo uma realidade específica, um comportamento de um grupo ou um indivíduo, explorando as possibilidades, nuances e subjetividades numa abordagem qualitativa. Assim sendo, o presente estudo trata da avaliação da sustentabilidade das Bacias PCJ, a partir do modelo de Gibson (2006), tendo como recorte os indicadores de disponibilidade hídrica e demandas hídricas, ou seja, o balanço hídrico.

Quanto ao procedimento técnico fez-se uso da pesquisa documental que, segundo Gil (2008), refere-se aos materiais que não receberam tratamento analítico. Como fontes de dados foram utilizados os documentos disponibilizados pela Agência das Bacias PCJ, intitulados "Construção do Plano de Bacias como um processo" e os documentos elaborados pelo Consórcio Profill-Rhama PCJ, intitulados "Relatório Final - anexos: Plano de Recursos Hídricos das Bacias Hidrográficas PCJ 2020 a 2035" e "Relatório Síntese: Plano de Recursos Hídricos das Bacias Hidrográficas PCJ 2020 a 2035"(AGÊNCIA DAS BACIAS PCJ, 2020; CONSÓRCIO PROFILLRHAMA PCJ, 2020a; CONSÓRCIO PROFILL-RHAMA PCJ, 2020b).

A análise dos resultados sustenta-se na discussão sobre a indicação dos Programas de Gerenciamento de Recursos Hídricos - ações, metas e indicadores quanto ao grau de prioridade atribuído pelo Plano das Bacias PCJ e a proposição de uma relação com o modelo de avaliação da sustentabilidade baseado nos princípios de Gibson.

O presente estudo foi desenvolvido a partir de quatro etapas metodológicas, conforme indicado na Figura 1. 
Figura 1- Etapas metodológicas da pesquisa

\begin{tabular}{|l|l|}
\hline Etapa 1 & •Seleção do modelo de Gibson para a avaliação de sustentabilidade \\
• Análise dos documentos disponibilizados pela Agência das Bacias PCJ e \\
documentos elaborados pelo Consórcio Profill-Rhama PCJ
\end{tabular}

A etapa 1 concentrou-se em uma revisão de literatura sobre a temática da sustentabilidade e do desenvolvimento sustentável, com vistas a buscar um modelo para embasar a avaliação de sustentabilidade do Plano das Bacias PCJ 2020-2035, no que se refere à disponibilidade e demandas hídricas, a partir dos indicadores, suas respectivas metas e ações. Com isso, optou-se pelo modelo de Gibson (2006) para indicar caminhos em direção à sustentabilidade das bacias em questão.

$\mathrm{Na}$ etapa 2, foram consultados os documentos disponibilizados pelas Agências das Bacias PCJ e aqueles elaborados pelo Consórcio Profill-Rhama PCJ. A seleção dos dados dos documentos teve como critério estar relacionado com o balanço hídrico das Bacias PCJ. Os Relatórios, Final e Síntese, que versam sobre o Plano de Recursos Hídricos das Bacias Hidrográficas dos rios Piracicaba, Capivari e Jundiaí 2020 a 2035 (CONSÓRCIO PROFILL-RHAMA PCJ, 2020a; CONSÓRCIO PROFILL-RHAMA
PCJ, 2020b) subsidiaram a discussão e análise dos resultados.

Quanto à etapa 3, adotou-se como critério para a seleção dos programas de gerenciamento de recursos hídricos e respectivas ações enumeradas no Quadro 1, o alinhamento com o Objetivo do Desenvolvimento Sustentável (ODS) 6 Assegurar a disponibilidade e a gestão sustentável da água e saneamento para todos da Agenda 2030. Plano de ação universal para o Desenvolvimento Sustentável, que tem como uma de suas metas alcançar o acesso universal e equitativo à água potável, segura e acessível para todos até o ano em questão (ONU, 2015).

A construção da discussão da sustentabilidade das Bacias PCJ à luz dos princípios de Gibson (2006), na quarta e última etapa, teve como principal critério o conteúdo contraído através dos documentos de Plano de bacias PCJ, de onde se propôs avaliar sua aproximação ou atendimento dos princípios de Gibson, a partir das ações presentes nos programas elencados no Quadro 2. 


\subsection{Contextualização da área de estudo}

As Bacias PCJ abrangem uma área aproximada de $15.320 \mathrm{~km}^{2}$, distribuídas em 76 municípios (71 no Estado de São Paulo e 5 em Minas Gerais), totalizando uma população estimada em 5,8 milhões de habitantes, concentrada principalmente em área urbana. A Bacia do Rio Piracicaba abriga a maior parte da população $(66,99 \%)$, os outros $16,55 \%$ estão localizados nas Bacias do Rio Jundiaí e
$16,45 \%$ no Rio Capivari. É uma região economicamente importante, com níveis elevados de Produto Interno Bruto (PIB) e Índice de Desenvolvimento Humano (IDH). As atividades econômicas exercidas na área das bacias incluem atividades industriais, agrícolas, de comércio e serviços, com destaque para o contínuo crescimento do setor de serviços e da indústria (CONSÓRCIO PROFILL-RHAMA PCJ, 2020b).

Figura 2- Mapa das Bacias Hidrográficas do PCJ

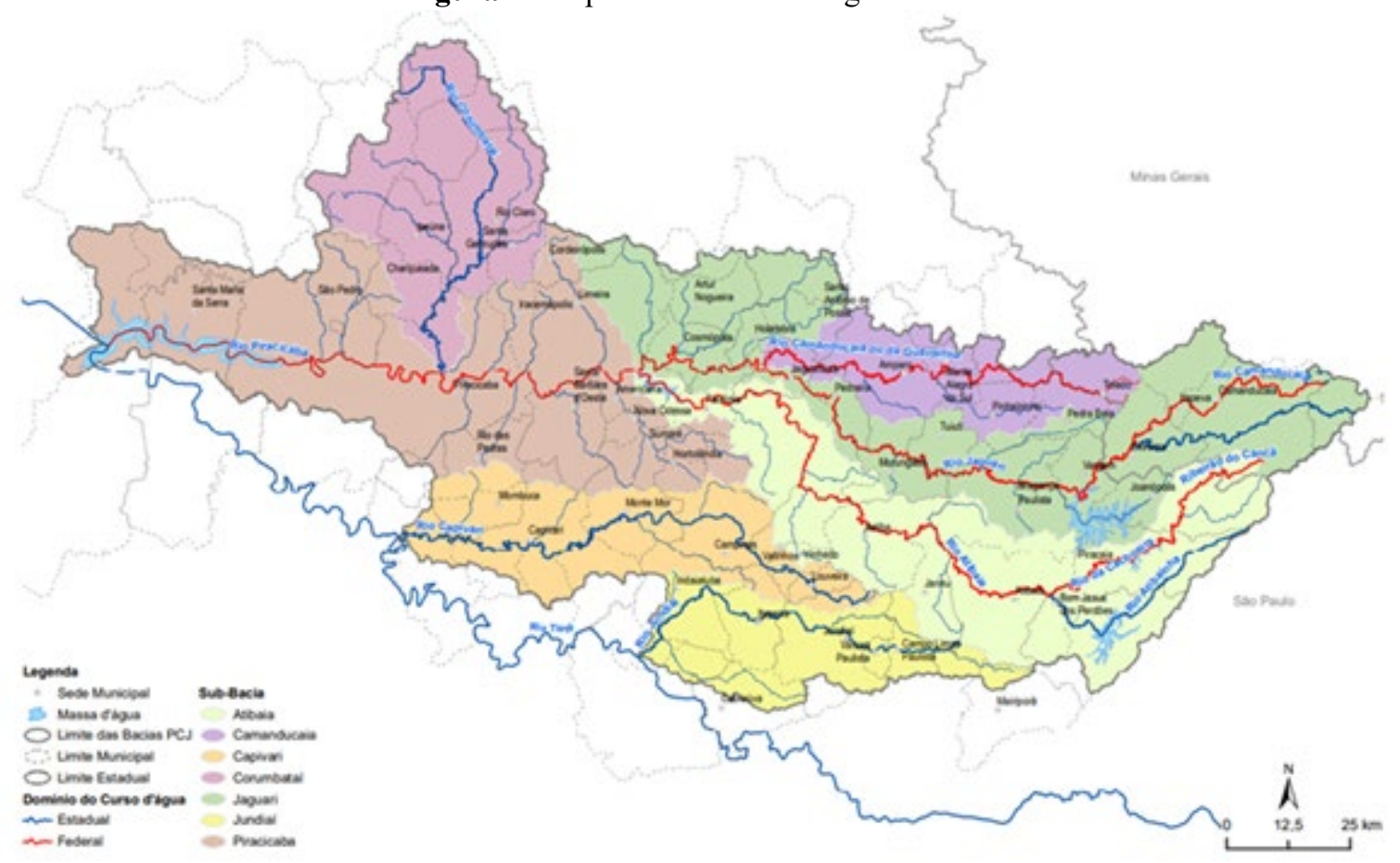

Fonte: Consórcio Profill-Rhama PCJ (2020b).

A construção do plano deu-se em etapas, sendo que a primeira focou na revisão e atualização do até então vigente PBH PCJ 2010-2020. Já as Etapas 2 e 3 foram direcionadas para a elaboração de cinco cadernos temáticos sobre os seguintes assuntos: Garantia do Suprimento Hídrico; Educação Ambiental, Integração e Difusão de Pesquisas e Tecnologias; Conservação e Uso da Água no Meio Rural e Recuperação Florestal; Águas Subterrâneas; e Enquadramento dos Corpos d'Água Superficiais. Tratou-se de um processo decisório aberto, integrando a equipe técnica responsável, as Câmaras Técnicas dos Comitês PCJ - através de reuniões e discussões entre elas - e a sociedade, por meio de consultas nas audiências públicas, antes da entrega dos produtos. Por último, a 
Etapa Final contou com a aprovação pelo Plenário dos Comitês PCJ do Relatório Final e do Relatório Síntese do PBH PCJ 2020-2035 (AGÊNCIA DAS BACIAS PCJ, 2020).

\section{APRESENTAÇÃO E DISCUSSÃO DOS RESULTADOS}

Nesta seção são apresentados os resultados do estudo a partir de dados obtidos no Plano de Bacias PCJ 2020-2035, elaborado pelo Consórcio Profill-Rhama PCJ (2020a). Para verificar em que medida o modelo de avaliação da sustentabilidade estudado pode ser aplicado nas Bacias PCJ, no atendimento da demanda de água em diferentes contextos, primeiramente foi identificado que o plano de bacias prevê ações relacionadas ao ODS 6 meta 6.1 da Agenda 2030 (ONU, 2015).

A seleção da meta 6.1 do ODS justifica-se por tratar do acesso à água de forma universal e equitativa para todos. Considerando essa meta foram identificados no Plano das Bacias PCJ os Eixos Temáticos e respectivos programas que abarcam o ODS 6 (Quadros 1 e 2).

Dentre os principais resultados discorre-se sobre a disponibilidade hídrica em relação à demanda; a importância da revisão de planos de controle e redução de perdas, a ampliação da disponibilidade hídrica; e a existência de planos de gestão com diretrizes para a preservação e geração de oportunidades e atendimento das necessidades das gerações atuais e futuras.

Quadro 1- Eixos temáticos estratégicos e respectivos programas do Plano de Bacias PCJ 2020-2035 selecionados

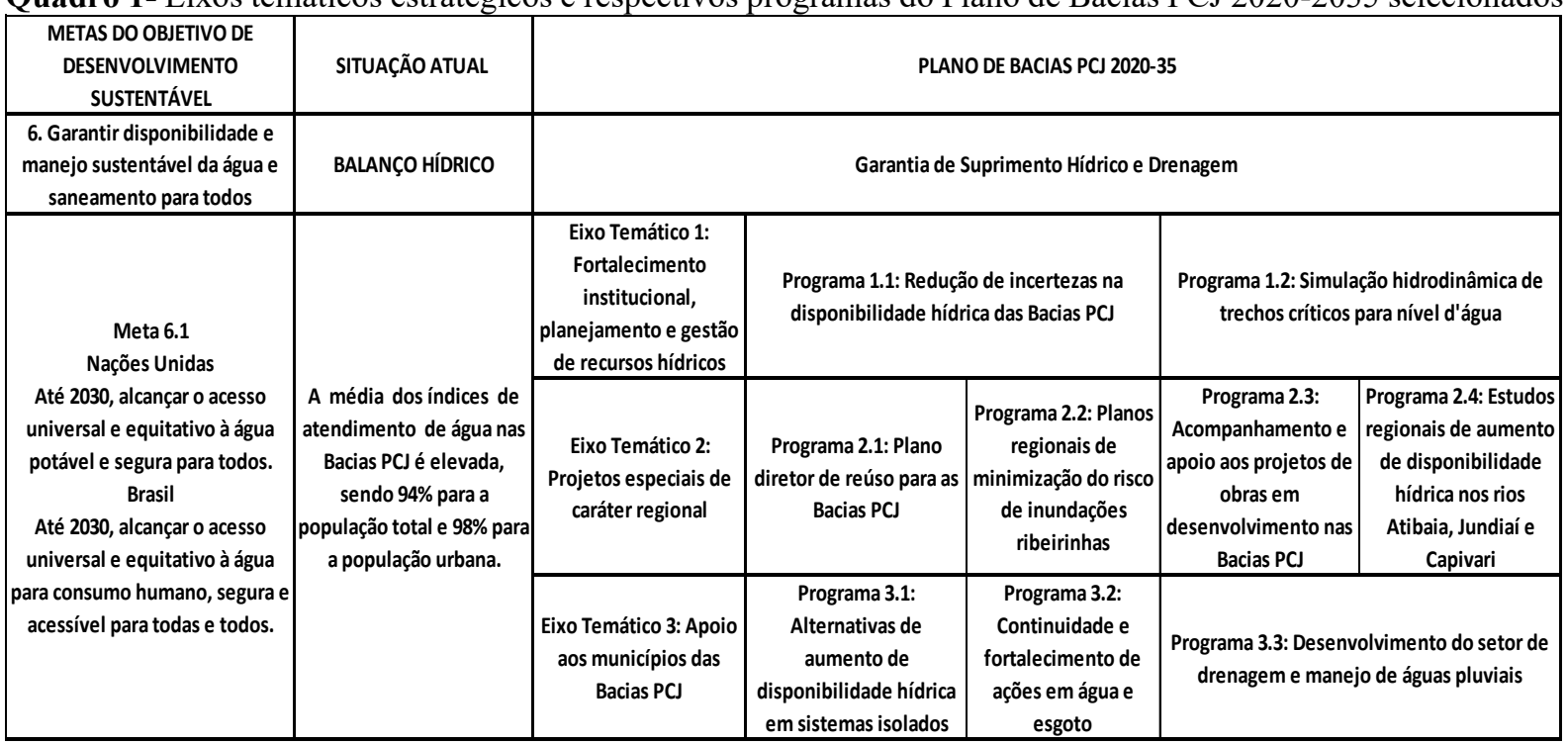

Fonte: Elaborado pelos autores, com base no PBH PCJ 2020-2035 (2020a).

O Plano das Bacias PCJ 2020-2035 revela a partir dos seus Programas que há diretrizes para a garantia de suprimento hídrico e drenagem (Quadro 1). Chama a atenção a situação do balanço hídrico ter um índice de atendimento de demanda de água elevado, ao atender a $94 \%$ da população total e $98 \%$ da população urbana. Esses dados revelam uma orientação ao princípio II "Suficiência de meios de subsistência e oportunidade", ao indicar condições de atendimento da demanda de água para uma vida decente como preconizado por esse princípio. 
atual e de longo prazo. Isso pode ser observado principalmente nas ações derivadas dos Programas 1.1 Redução de incertezas na disponibilidade hídrica das bacias e 1.2 Simulação hidrodinâmica de trechos críticos para nível de água.

O desafio de contemplar a gestão dos indicadores de disponibilidade versus demandas na agenda dos municípios, atendidos pelos rios das Bacias PCJ, requer a clara definição de metas prioritárias para a garantia do suprimento hídrico à população. Considerando a projeção de demanda crescente de 2020 até 2035 para abastecimento público (11\%), indústria $(18 \%)$, irrigação $(52 \%)$ e dessedentação animal (72\%), o Relatório Síntese PCJ (2020) enfatiza a tendência para um desequilíbrio entre demanda e disponibilidade de água e a necessidade de incentivar os municípios a implantar projetos de regularização das vazões, redução de demanda e diminuição de perdas no abastecimento. No horizonte de longo prazo, a proposta para a retomada do balanço hídrico inclui, também, o reuso de água, a transposição de rios e o uso de reservas subterrâneas com cautela e mediante estudos mais específicos, diante das incertezas e riscos sobre a exploração dessas águas e a necessidade de dados mais precisos (CONSÓRCIO PROFILLRHAMA PCJ, 2020b). 
Quadro 2- Ações do Plano das Bacias PCJ 2020-2035 em relação aos critérios de Gibson

\begin{tabular}{|c|c|c|c|c|c|c|c|c|c|c|c|c|}
\hline \multicolumn{5}{|c|}{ PLANO DAS BACIAS 2020-35 } & \multicolumn{8}{|c|}{$\begin{array}{l}\text { CRITÉRIOS DE GIBSON } \\
\text { ATENDIDOS }\end{array}$} \\
\hline $\begin{array}{l}\text { PROGRAMAS DE } \\
\text { GERENCIAMENTO } \\
\text { DOS RECURSOS } \\
\text { HÍDRICOS }\end{array}$ & $A C ̧ \tilde{A} O$ PREVISTA & META & INDICADOR & $\begin{array}{l}\text { PRIORIDA } \\
\text { DE }\end{array}$ & I & II & III & IV & $\mathrm{v}$ & VI & VII & VIII \\
\hline Programa 1.1 & $\begin{array}{l}\text { Manutenção e Aprimor amento de um } \\
\text { Modelo Chura-Vazão para as Bacias } \\
\text { PCJ; }\end{array}$ & Disporibilidade de um modelo & $\begin{array}{l}\text { Documentaç ão da } \\
\text { ex ecu̧̧⿻弋一 da ação }\end{array}$ & Muito Alta & $\mathrm{x}$ & $x$ & $\mathrm{x}$ & $\mathrm{x}$ & & & & $\mathrm{x}$ \\
\hline \multirow{3}{*}{ Programa 1.2} & 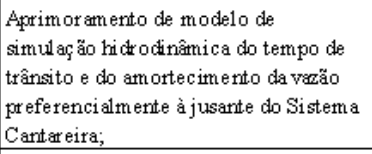 & Modelo Calibrado & $\begin{array}{l}\text { Meses de contrato (atual } \\
\text { sobre o previsto) }\end{array}$ & Média & $\mathrm{x}$ & & & & & & $\mathrm{x}$ & $\mathrm{x}$ \\
\hline & $\begin{array}{l}\text { Estudo de regras de operação das } \mathrm{PCH} \\
\text { par a minimização do conflito com } \\
\text { abastecimento; }\end{array}$ & Relatório técrico & $\begin{array}{l}\text { Meses de contrato (atual } \\
\text { sobre o previsto) }\end{array}$ & Muito Baixa & & & & & $\mathrm{x}$ & & $\mathrm{x}$ & \\
\hline & $\begin{array}{l}\text { Previsão de rívis par a energia } \\
\text { navegaç ão e abastecim ento na Sala de } \\
\text { Situação PCJ. }\end{array}$ & Sistema operacional & $\begin{array}{l}\text { Meses de contrato (atual } \\
\text { sobre o previsto) }\end{array}$ & Muito Baixa & & & & & $\mathrm{x}$ & & & $\mathrm{x}$ \\
\hline Programa2.1 & $\begin{array}{l}\text { Elaboraça do plano diretor de reuso de } \\
\text { áqua para as Bacias PCJ. }\end{array}$ & P1 ano el aborado & $\begin{array}{l}\text { Meses de contrato (atual } \\
\text { sobre o previsto) }\end{array}$ & Média & & & & & & $\mathrm{x}$ & $\mathrm{x}$ & \\
\hline Programa2.2 & $\begin{array}{l}\text { Deservol vimento de estudos de } \\
\text { alternativas e intervençöes para } \\
\text { mirimizaç ão dos risc os de inundação } \\
\text { ribe iririha. }\end{array}$ & $\begin{array}{l}\text { Planos el abor ados por subbacia } \\
\text { e intervenção }\end{array}$ & $\begin{array}{l}\text { Meses de contrato (atual } \\
\text { sobre o previsto) }\end{array}$ & Média & & & & & $\mathrm{x}$ & $\mathrm{x}$ & $\mathrm{x}$ & \\
\hline Programa2.3 & $\begin{array}{l}\text { Acomparhamento e apoio aos e studos } \\
\text { de viabilidade, projetos de engenharia e } \\
\text { licenciamento ambiental das barragens } \\
\text { de Pedreira, Duas Pontes e do ribeirão } \\
\text { Pir í e do trecho Oeste do SAR: }\end{array}$ & $\begin{array}{l}\text { Defirição de GT; Relatórios } \\
\text { periódicos }\end{array}$ & $\begin{array}{l}N^{\circ} \text { de relatórios } \\
\text { periódicos com relação } \\
\text { ao total previsto }\end{array}$ & Média & & & & & & $\mathrm{x}$ & $\mathrm{x}$ & $\mathrm{x}$ \\
\hline Programa 2.4 & $\begin{array}{l}\text { Desenvolvimento de estudo de } \\
\text { alternativas de aumento da } \\
\text { disporibilidade hídrica nas subbacias } \\
\text { dos rios Atibaia J undiai e Capivari. }\end{array}$ & $\begin{array}{l}\text { Elabor ação de ao menos } 01 \\
\text { estudo }\end{array}$ & $\begin{array}{l}\text { Documentaç ão da } \\
\text { ex ecư̧ão da ação }\end{array}$ & Muito Alta & & $\mathrm{x}$ & & & & $\mathrm{x}$ & & $\mathrm{x}$ \\
\hline \multirow{2}{*}{ Programa3.1 } & $\begin{array}{l}\text { Estudos de viabilidade para aumento de } \\
\text { re gul arizaç ão de vacóes em m ananciais } \\
\text { existente s novos barr amentos }\end{array}$ & $\begin{array}{l}\text { Termos de referência; } E \text { studo } \\
\text { elaborado }\end{array}$ & $\begin{array}{l}\text { Proje to elaborado por } \\
\text { município sobre o } \\
\text { rúmero total (33) }\end{array}$ & Alta & & $\mathrm{x}$ & $x$ & $\mathrm{x}$ & & & $\mathrm{x}$ & $\mathrm{x}$ \\
\hline & $\begin{array}{l}\text { Estudos hidroge ológic os par a } \\
\text { explor ação sustentável de águas } \\
\text { subterrầne as. }\end{array}$ & $\begin{array}{l}\text { Termos de referência; Estudo } \\
\text { elaborado }\end{array}$ & $\begin{array}{l}\text { Meses de contrato (atual } \\
\text { sobre o previsto) }\end{array}$ & Baixa & & & & & $\mathrm{x}$ & & & $\mathrm{x}$ \\
\hline \multirow{4}{*}{ Programa3.2 } & $\begin{array}{l}\text { Controle de perdas em sistemas de } \\
\text { abastecimento de água; }\end{array}$ & $\begin{array}{l}\text { Alc ance das metas } \\
\text { intermediárias dos cenários de } \\
\text { ref erência para plane jamento, } \\
\text { conforme descrito no Quadro } \\
23.4 \text { do Plano de Bacias } \\
\end{array}$ & $\begin{array}{l}\text { Índice de per das na } \\
\text { distribuição }\end{array}$ & Alta & & $\mathrm{x}$ & & & $\mathrm{x}$ & & & $\mathrm{x}$ \\
\hline & $\begin{array}{l}\text { Diagnóstico da capacidade e } \\
\text { compromisso dos muricípios; }\end{array}$ & Relatório técrico & $\begin{array}{l}\text { Meses de contrato (atual } \\
\text { sobre o previsto) }\end{array}$ & B sixa & $\mathrm{x}$ & $\mathrm{x}$ & & & & & & $\mathrm{x}$ \\
\hline & $\begin{array}{l}\text { Elaboração e revisão de P1anos de } \\
\text { Controle e Redução de Perdas }\end{array}$ & $\begin{array}{l}\text { Todos os Planos de perdas dos } \\
\text { municípios das Bacias PCJ } \\
\text { revisados }\end{array}$ & $\begin{array}{l}\text { Documentaç ão da } \\
\text { ex ecução da ação }\end{array}$ & Alta & $\mathrm{x}$ & $\mathrm{x}$ & & & & $\mathrm{x}$ & $\mathrm{x}$ & \\
\hline & $\begin{array}{l}\text { Marutenção do projeto de } \\
\text { benchm arking para o contr ole de perdas } \\
\text { de água em sistemas de distribuição. }\end{array}$ & $\begin{array}{l}\text { Ao menos } 01 \text { mamutenção do } \\
\text { projeto re alizada }\end{array}$ & $\begin{array}{l}\text { Documentaç ão da } \\
\text { ex ecuŗão da ação }\end{array}$ & Muito Alta & $\mathrm{x}$ & $\mathrm{x}$ & & & & & $\mathrm{x}$ & \\
\hline \multirow[b]{2}{*}{ Programa 3.3} & $\begin{array}{l}\text { Elaboração de um guia de manejo de } \\
\text { drenagem e manejo de águas pluxiais; }\end{array}$ & Mamual el abor ado & $\begin{array}{l}\text { Número de marmais } \\
\text { elaborados sobre o total } \\
\text { de muricípios prioritários }\end{array}$ & Média & & & & & $\mathrm{x}$ & $x$ & & $\mathrm{x}$ \\
\hline & $\begin{array}{l}\text { Elaboração dos P1 anos Diretores de } \\
\text { Drenagem Urbana e Manejo de Águas } \\
\text { Pluviais }\end{array}$ & $\begin{array}{l}\text { E1abor ação de ao menos } 01 \\
\text { P1ano, consi der ando os trechos } \\
\text { vulner áveis indicados no P1ano } \\
\text { de Bacias }\end{array}$ & $\begin{array}{l}\text { Documentaç ão da } \\
\text { ex ecução da ação }\end{array}$ & Alta & & & $\mathrm{x}$ & $\mathrm{x}$ & & $\mathrm{x}$ & $\mathrm{x}$ & \\
\hline
\end{tabular}

Fonte: Elaborado pelos autores, com base no PBH PCJ 2020-2035 (2020a).

Em relação à disponibilidade hídrica das Bacias PCJ, observa-se crescente demanda por água, condição que afeta o balanço hídrico, apresentando relação com o princípio Integridade do sistema socioecológico. Como apontado no Relatório Síntese PCJ (2020), os indicadores precisam ser analisados considerando a variável população. Para a aplicação do primeiro princípio de Gibson é necessário observar a integridade da água no que tange à disponibilidade versus demanda, isso é, o balanço hídrico. Isso pode contribuir para identificar a 
capacidade de suporte das Bacias PCJ para atender a demanda com integridade, no longo prazo, sem comprometer o ecossistema, e colocar em risco as demais atividades presentes no contexto dessas bacias.

Para analisar o alinhamento do princípio integridade do sistema socioecológico com as ações previstas no Plano de Bacias PCJ 2020-2025, toma-se como exemplo o "diagnóstico da capacidade e compromissos dos municípios", ação elencada no Plano como sendo de baixa prioridade. Aqui indica-se que o acompanhamento contínuo e adaptativo da capacidade de suporte das Bacias PCJ requer a internalização dessa questão, nos âmbitos local e regional das agendas de governo. Já a ação orientada para a elaboração e revisão de planos de controle e redução de perdas é destacada como de alta prioridade no Programa 3.2 (Quadro 2). Esses exemplos, permitem ilustrar os pontos de alavancagem para acelerar as mudanças quanto ao balanço hídrico visando a redução de perdas.

Quanto ao segundo princípio Suficiência de meios de subsistência e oportunidades -, as ações previstas no Plano de Bacias 2020-2035 indicam caminhos para o desenvolvimento de estudos de alternativas de aumento da disponibilidade hídrica nas sub-bacias PCJ, e sendo essa ação de muito alta prioridade (Programa 2.4). O estudo de regras de operação das pequenas centrais hidrelétricas para minimização do conflito de abastecimento (Programa 1.2) tem prioridade muito baixa (Quadro 2). Embora os dados de balanço hídrico das Bacias PCJ revelem o atendimento de $94 \%$ da população, como já apontado anteriormente, o modelo de avaliação de sustentabilidade de Gibson pode contribuir para indicar alternativas de ampliação da disponibilidade hídrica, como pontos de alavancagem do Plano de Bacias 20202035.
Em relação ao princípio equidade intrageracional e equidade intergeracional, diretrizes para a preservação e geração de oportunidades, com foco no atendimento das necessidades das gerações atuais e futuras, encontram respaldo nas seguintes ações destacadas no Quadro 2: Planos diretores de drenagem urbana e manejo de águas pluviais e Estudo de viabilidade para aumento de regularização de vazões de mananciais existentes e novos barramentos. Verifica-se que a sustentabilidade das bacias está atrelada às condições de atendimento de demandas da sociedade, sem desconsiderar, por exemplo, a capacidade de drenagem urbana e vazões dos mananciais.

Observa-se que o princípio "Manutenção de recursos naturais e eficiência", que tem por finalidade garantir meios de subsistência mais sustentáveis e reduzir as ameaças à integridade de sistemas socioecológicos (GIBSON, 2006), pode ser aplicado ao Programa 2.2 Planos regionais de minimização do risco de inundações ribeirinhas dentro do Eixo Temático 2: Projetos especiais de caráter regional ao considerar, como apontado no Plano das Bacias PCJ, a importância dos planos regionais na previsão de ações com foco na gestão da ocorrência de eventos extremos, para a preservação da água. Salienta-se, de acordo com relatório do Consórcio PROFILL-RHAMA PCJ (2020b, p. 44) que uma forma de contribuir para a preservação do recurso água é a adoção de medidas para o controle de risco com a construção de "reservatórios, diques e o aumento da capacidade de escoamento", para isso, "as principais medidas não estruturais propostas são o zoneamento de inundações, a elaboração de Planos Diretores de Drenagem Urbana, a previsão de vazão e o alerta de inundações”. Essa é uma das razões pela qual o Programa 2.2 foi considerado como importante na preservação da água ao combater, por exemplo, inundações em zonas urbanas. 


\section{(CONSÓRCIO PROFILL-RHAMA PCJ,} 2020b).

Nesse ambiente, a identificação dos municípios com maiores demandas por subbacia contribui para as ações de controle de perdas em sistemas de abastecimento de água. Exemplo disso é a elaboração de Planos de Controle e Redução de Perdas e sua revisão. Ademais, o Plano prevê a elaboração dos Planos Diretores de Drenagem Urbana e Manejo de Águas Pluviais com alta prioridade, evidenciando o aspecto de eficiência do princípio de Gibson. Uma das ações do programa 2.2 é o desenvolvimento de estudos de alternativas e intervenções para minimização de riscos de inundação ribeirinha - os estudos são realizados por sub-bacia, priorizando as bacias com municípios que apresentam problemas recorrentes de inundação ribeirinha, e as intervenções contemplam medidas estruturais como limpeza e desassoreamento das calhas dos rios, o que caracteriza a manutenção de recurso natural.

Do ponto de vista do princípio Civilidade socioecológica e governança democrática que, segundo Gibson (2006), tem por base o processo decisório aberto e a promoção da consciência recíproca e responsabilidade coletiva nas tomadas de decisão, a partir do Plano de bacias PCJ, observa-se diretrizes que incentivam órgãos como os municípios e as agências reguladoras e concessionárias, entre outros atores, na elaboração conjunta de estudos para atender os requisitos de sustentabilidade.

Em complemento, encontra-se uma oportunidade de tornar o processo de gestão da água participativo, integrado, o que pode contribuir para uma sociedade bem informada, consciente e com senso de coletividade. No Plano de bacias PCJ, notase a ênfase na construção participativa de estudos para melhorar as condições de disponibilidade hídrica nas sub-bacias dos rios Atibaia, Jundiaí e Capivari. Como exemplo da governança democrática expressa em ações coletivas constantes no
Plano tem-se a Elaboração e revisão de Planos de Controle e Redução de Perdas; e Elaboração dos Planos Diretores de Drenagem Urbana e Manejo de Águas Pluviais, que estão alinhadas por exemplo com os Programas 2.1, 2.2 e 3.1 do Quadro 2 (CONSÓRCIO PROFILL-RHAMA PCJ, 2020b).

Em relação ao sétimo princípio "Precaução e adaptação", os dados apresentados de disponibilidade e demanda hídrica nas Bacias PCJ fornecem informações sobre as quantidades e necessidades de água para o abastecimento local. Esses dados podem ajudar no planejamento do consumo de água em momento de escassez desse recurso, possibilitando o planejamento de ações de abastecimento ou o racionamento do consumo nesses períodos, reduzindo o uso em atividades menos importantes ou menos impactantes para o funcionamento das atividades da área estudada, atendendo ao Programa 2.1. Essas ações podem contribuir com a precaução e adaptação em situações de escassez e fomentar a gestão adaptativa.

Em última análise, com relação ao oitavo princípio, que tem por base integrar os pilares da sustentabilidade, levando em consideração o curto e o longo prazo, podese observar, por intermédio do Relatório elaborado pelo Consórcio Profill-Rhama PCJ (2020a), destaque para o aumento de disponibilidade hídrica (Programas 2.4 e 3.1). Constatou-se a preocupação em avaliar de forma perene o impacto das atividades presentes e as condições das bacias PCJ, a fim de garantir a conservação e recuperação dos corpos d'água e nascentes.

As obras de regularização de vazões e transposições podem aumentar as vazões disponíveis para os usos da água, ao passo que se observa, que as Bacias PCJ estão localizadas em um eixo com crescimento econômico e consequente crescimento de demandas hídricas para abastecimento, irrigação e atividades industriais a longo prazo. 


\section{CONCLUSÕES}

O estudo sobre a possibilidade de aplicação do modelo de avaliação da sustentabilidade com base nos princípios de Gibson, no contexto das Bacias PCJ, permitiu que se observasse aderência desse modelo com os Programas de Gerenciamento de Recursos Hídricos, suas ações, metas e indicadores selecionados no relatório do Consórcio Profill-Rhama PCJ (2020a).

No tocante aos resultados obtidos, o presente estudo, nesta seção, referiu-se ao atendimento da demanda de água pelas Bacias PCJ, pautados nos critérios de avaliação da sustentabilidade propostos por Gibson (2006). Para tanto, no decorrer da discussão foram apresentados elementos do Plano de bacias PCJ e sua relação com os princípios de Gibson.

Dentre os principais resultados discorreu-se sobre a disponibilidade hídrica em relação à demanda; a importância da revisão de planos de controle e redução de perdas, a ampliação da disponibilidade hídrica; e a existência de planos de gestão com diretrizes para a preservação e geração de oportunidades e atendimento das necessidades das gerações atuais e futuras.

Diante do exposto, sugere-se um direcionamento para a integração entre os pilares da sustentabilidade, com destaque às ações para redução do consumo. A partir, por exemplo, de programas de educação e política ambiental aplicada à população em cada contexto social - contemplando os demais pilares. Isso pode contribuir para uma mudança comportamental, com a redução do consumo, visando a manutenção do seu nível abaixo da capacidade de suporte, garantindo acesso com a mesma qualidade para as futuras gerações.

Através dos resultados pode-se dizer que a análise dos princípios de Gibson quanto à sua viabilidade para o acompanhamento e a evolução das metas e indicadores, no contexto dos Planos de bacias hidrográficas, mostra-se um desafio que pode ser superado. $\mathrm{O}$ aprofundamento do estudo, bem como a sua replicação em estudos similares, pode ser conduzido a partir da incorporação de dados pormenorizados não expressos no Plano de Bacias. Tais elementos podem revelar o contexto para a concepção e o delineamento de cada programa e suas respectivas ações.

Neste estudo, a avaliação da sustentabilidade das bacias hidrográficas PCJ que considere um modelo integrativo, como proposto a partir dos princípios de Gibson, mostra-se deveras importante como instrumento de gestão para o monitoramento dos recursos hídricos. Apesar da avaliação da sustentabilidade das Bacias PCJ ser uma prática presente, estudos complementares de modelos de avaliação que discutam as dimensões da sustentabilidade sem compensação de trade-off trazem benefícios pela sua característica enquanto abordagem sistêmica.

O método de avaliação baseado nos princípios de Gibson fornece, ainda, alicerce para identificar os programas e metas de gerenciamento de recursos hídricos que valorizam a participação da sociedade civil nas decisões junto aos colegiados, bem como a articulação interinstitucional como fatores primordiais para a construção coletiva da sustentabilidade das Bacias PCJ.

A indicação das prioridades das ações de cada programa do Plano de Bacias PCJ 2020-2035 revela a existência de pontos de alavancagem para acelerar as mudanças. Essas possibilitam não apenas quantificar, mas também qualificar as questões que envolvem, por exemplo, o balanço hídrico. Por isso, recomenda-se ter claro qual a mudança pretendida em relação ao balanço hídrico para, posteriormente, definir sua aderência ou não ao modelo de avaliação da sustentabilidade. 
Fomentar discussões sobre o comportamento das variáveis que impactam o balanço hídrico, como o crescimento das populações urbana e rural nas Bacias PCJ e suas sub-bacias requer um planejamento de mobilização de agentes da sociedade e não apenas das agências reguladoras, instâncias municipais, estaduais ou federais. Tais aspirações estão indissoluvelmente ligadas à civilidade socioambiental e à governança democrática. Por isso, as questões aparentemente técnicas por mudanças de protocolos precisam ser previstas quando se pensa em aprimorar o processo de avaliação da sustentabilidade das Bacias PCJ.

Conclui-se que a sustentabilidade das Bacias PCJ, no tocante ao indicador balanço hídrico, deve considerar as particularidades da dinâmica do balanço nos usos distintos de cada sub-bacia. Entende-se que os princípios de Gibson podem contribuir para avaliar as propostas de ação dos programas constantes no Plano de bacias, ao permitir mensurar as metas a partir dos indicadores relacionados com a espacialização das demandas e do saldo hídrico. Assim, pode-se oferecer um direcionamento às questões de integridade do sistema ecológico ao mitigar riscos de danos graves ou irreversíveis, na linha da precaução e adaptação. Nessa linha, percebe-se que a capacidade suporte dos recursos hídricos para a garantia de água em qualidade e quantidade na perspectiva preconizada pelo princípio integração entre situação atual e de longo prazo é um elemento presente nos programas do Plano de Bacias PCJ e que se alinha ao preconizado pela meta 6.1 dos Objetivos do Desenvolvimento Sustentável.

\section{AGRADECIMENTOS}

O presente trabalho foi realizado com apoio da Coordenação de Aperfeiçoamento de Pessoal de Nível Superior - Brasil (CAPES) - Código de Financiamento 001.

\section{REFERÊNCIAS}

AGÊNCIA DAS BACIAS PCJ. A construção do Plano de Bacias como um processo. 2020. Disponível em: https://plano.agencia.baciaspcj.org.br/oplano. Acesso em: 16 out. 2020.

AGÊNCIA NACIONAL DE ÁGUAS E SANEAMENTO BÁSICO (ANA). Manual de Usos Consuntivos da Água no Brasil. Brasília: ANA, 2019. Disponível em: $\quad$ http://snirh.gov.br/usos-da-agua/. Acesso em: 26 out. 2020.

AGÊNCIA NACIONAL DE ÁGUAS E SANEAMENTO BÁSICO (ANA). Conjuntura dos recursos hídricos no Brasil 2020: Informe anual. Brasília: ANA, 2020. 118p.

AMORIM, W. A. C. et al. Capital humano e sustentabilidade: uma proposta de abordagem multidisciplinar. Gestão \& Regionalidade, v. 31 , n. 92, p. 151-163, 2015.

AYRES, R. U.; VAN DEN BERGH, J. C. J. M.; GOWDY, J. M. Viewpoint: weak versus strong sustainability, 98-103/3, Tinbergen Institute, 1998. Disponível em: https://papers.tinbergen.nl/98103.pdf.

Acesso em: 26 nov. 2020.

CARVALHO, J. R. M.; CARVALHO, E. K. M. A.; CURI, W. F. Avaliação da sustentabilidade ambiental de municípios Paraibanos: uma aplicação utilizando o método Promethee II. Gestão \& Regionalidade, v. 27, n. 80, p. 71-84, 2011.

COLLISCHONN, W.; DORNELLES, F. Hidrologia para Engenharia e Ciências Ambientais. 2. ed. Porto Alegre: ABRH, 2015. 336 p.

COMISSÃO MUNDIAL SOBRE MEIO AMBIENTE E DESENVOLVIMENTO (CMMAD). Nosso futuro comum. Rio de Janeiro: Fundação Getúlio Vargas, 1988. 
CONSÓRCIO PROFILL-RHAMA PCJ. Relatório Final - Anexos: Plano de Recursos Hídricos das Bacias Hidrográficas dos rios Piracicaba, Capivari e Jundiaí, 2020 a 2035. Porto Alegre, 2020a. 569 p.

CONSÓRCIO PROFILL-RHAMA PCJ. Relatório Síntese: Plano de Recursos Hídricos das Bacias Hidrográficas dos rios Piracicaba, Capivari e Jundiaí, 2020 a 2035. Porto Alegre, 2020b. 140 p.

DIAMOND, J. Colapso: Como as Sociedades Escolhem o Fracasso ou o Sucesso. Rio de Janeiro: Editora Record, 2005.

GIBSON, R. B.; HASSAN, S.; HOLTZ, S.; TANSEY, J.; WHITELAW, G. Sustainability assessment: criteria and processes. London, Sterling, VA: Earthscan, 2005.

GIBSON, R. B. Beyond the pillars: sustainability assessment as a framework for effective integration of social, economic and ecological considerations in significant decision-making. Journal of Environmental Assessmnt Policy and Management v. 8, n. 3 p. 259-280, 2006.

GIL, Antônio Carlos. Como elaborar projetos de pesquisa. 4 ed. São Paulo: Atlas, 2008.

HACKING, T., GUTHRIE, P. A framework for clarifying the meaning of Triple Bottom-Line, Integrated, and Sustainability Assessment. Environmental Impact Assessment Review, v. 28, n. 2-3, p. 73-89, 2007.

HODGE, R. A.; HARDI, P.; BELL, D. V. J. Seeing change through the lens of sustainability. Beyond Delusion: Science and Policy Dialogue on Designing Effective Indicators of Sustainability Development.
Costa Rica. The International Institute for Sustainable Development, 1999.

HUESEMANN, M. H. The failure of ecoefficiency to guarantee sustainability: Future challenges for industrial ecology. Environmental Progress, v. 23, n.4, p. 264-210, 2004.

KATES, R. W.; PARRIS, T. M.; LEISEROWITZ, A. A. What is sustainable development? Goals, indicators, values, and practice. Environment: Science and Policy for Sustainable Development, v. 47, n. 3, p. 8-21, 2005.

MEBRATU, D. Sustentabilidade e Sustentável Desenvolvimento: histórico e revisão conceitual. Ambiente Impacto Assess Rev., v. 18, 1998.

MEADOWS, Donella Hager. Indicators and information systems for sustainable development. A report to the balaton group. The Sustainable Institute. 1998.

MORRISON-SAUNDERS, A., POPE, J. Conceptualising and managing trade-offs in sustainability assessment. Environmental Impact Assessment Review, v. 38, p. 5463, 2013.

MENEZES, U. G.; DIAS, V. V.; GOMES, C. M. O paradigma sustentável e a formulação de estratégias empresariais para a competitividade. Gestão \& Regionalidade, v. 26, n. 78, p. 4-17, 2010.

NESS, B. et al. Categorising tools for sustainability assessment. Ecological Economics, 60, p. 498-508, 2007.

ORGANIZAÇÃO DAS NAÇÕES UNIDAS. ONU. Transformando nosso mundo: A Agenda 2030 para o desenvolvimento sustentável. Nações Unidas, 2015. 
RICHARDSON, R. J. Pesquisa social: métodos e técnicas. 4.ed., São Paulo: Atlas, 2017.

SARAIVA, P. et al. O uso de tecnologias como estratégia na construção de cidades mais inteligentes e sustentáveis. Gestão \& Regionalidade, v. 35, n. 105, p. 184-199, 2019.

SARTORI, S.; LATRÔNICO, F.; CAMPOS, L. M. S. Sustentabilidade e Desenvolvimento Sustentável: uma taxonomia no campo da literatura. Ambiente \& Sociedade, v. 17, n. 1, p. 122, 2014.

SICHE, J. R. et al. Sustainability of nations by indices: Comparative study between environmental sustainability index, ecological footprint and the energy performance indices. Ecological Economics, v. 66, n.4, p. 628-637, 2008.

SILVA, I. R. et al. Diagnóstico ambiental e avaliação da capacidade de suporte das praias do bairro de Itapoã, Salvador, Bahia. Sociedade \& Natureza, v. 21, n. 1, p. 7184, abr. 2009.

SLIMANE, M. Role and relationship between leadership and sustainable development to release social, human, and cultural dimension. Social and Behavioral Sciences, v. 41, 2012.

WCED. Our common Future. Oxford: Oxford University Press, 1987.

\footnotetext{
${ }^{\text {i }}$ Cibele Roberta Sugahara

Doutora em Ciência da Informação. Universidade de São Paulo (USP).

Professora da Faculdade de Administração e Pesquisadora do Programa de Pós-Graduação em Sustentabilidade da Pontifícia Universidade Católica de Campinas - PUC Campinas.
}

\section{ii Audrey Moretti Martins}

Doutoranda em Engenharia Hidráulica e Saneamento na Universidade de São Paulo - EESC/USP. Professora da Universidade de Araraquara - UNIARA.

\section{iii Lorena Braga Quintella Jucá}

Mestranda em Engenharia Hidráulica e Saneamento na Escola de Engenharia de São Carlos da Universidade de São Paulo (EESC/USP), São Carlos, São Paulo (SP), Brasil.

Bacharela em Engenharia Ambiental e Sanitária pela Universidade Federal de Alagoas - UFAL.

\section{iv Duarcides Ferreira Mariosa}

Doutor em Sociologia. Professor e Pesquisador no Programa de Pós-graduação em Sustentabilidade da Pontifícia Universidade Católica de Campinas (PUC-Campinas), Campinas, São Paulo, Brasil. 